\title{
The Stability of Ecosystems Cryolithozone in the Extraction Hydrocarbon Feedstock
}

\author{
Yana Legostaeva, Marta Ksenofontova, Anna Gololobova \\ Institute of Applied Ecology of the North, M.K. Ammosov North- Eastern Federal University \\ 1 Lenin Avenue, Yakutsk, Russia \\ yb.legostaeva@s-vfu.ru; mi.ksenofontova@s-vfu.ru; ag.dyagileva@s-vfu.ru
}

\begin{abstract}
The results of the analysis of trace-element composition of the major abiotic components of ecosystems oil fields located in the permafrost zone - snow cover, permafrost soils, natural surface water and sediment are presented in the article. Snow is characterized by a weakly acidic medium with mineralization $8,4-14,9 \mathrm{mg} / \mathrm{dm} 3$ with very soft water, on the sites of acting wells of the field. The composition of the snow water is mainly hydrocarbonate class with a predominance of calcium and magnesium cations. The majority of the analyzed of ash elements are in a soluble state, in microelement composition of snow water are fixed $\mathrm{Mn}, \mathrm{Cu}$ and total Fe. Soils of natural landscapes of study territory are characterized by a weakly acidic or near neutral $\mathrm{pH}$ in the upper organic horizons and weakly alkaline $\mathrm{pH}$ in the mineral part of the soil profile, and with sufficiently high content of humus and high cation exchange capacity. Soils technogenically transformed landscapes are characterized by weakly alkaline and alkaline $\mathrm{pH}$, organic matter content and the cation exchange capacity varies widely. On the example of the microelement characteristics of the soil cover on the territory of oil and gas field are traced variation content of mobile forms of trace elements in soils. The activities of the oil and gas complex of significant impact on the quality of natural waters does not exert, at the moment of study. Microelement spectrum of sediments are characterized by the accumulation of mobile forms of $\mathrm{Ni}, \mathrm{As}, \mathrm{Cr}, \mathrm{Cu}, \mathrm{Cd}$. The impact of oil and gas complex in the study region is manifested of locally at the moment, but is irreversible.
\end{abstract}

Keywords: cryolithozone, stability of frozen soils, technogenic-transformed landscapes, abiotic components of the ecosystem, mobile forms of trace elements

\section{Introduction}

The fragile natural situation of the permafrost zone, where main part of feedstock and increasing potential of mining production in the North-East of Russia are currently focused, often leads to irreversible ecological consequences during the development of the northern regions. It is well known that the consequences of development of mineral deposits, including hydrocarbons, is degradation or complete destruction of the natural landscape, which is reflected in changes in the chemical properties and characteristics of the main abiotic components of the ecosystem.

Features of structural-tectonic structure of the territory of the permafrost zone, the nature and chemistry mineralized waters, availability of natural geochemical anomalies caused by the processes of formation of kimberlite fields and oil and gas bearing area is highlighted as a whole Western Yakutian region in the vast area of Eastern Siberia. The paper describes the main findings of the evaluation of modern ecological and geochemical state of the main abiotic components of terrestrial and aquatic ecosystems on the example of the oil fields.

\section{Methods}

Material for this article was prepared on the basis of generalization of fund data of Institute of Applied Ecology of the North for Malo-Botuobinsky territory, including Sredne-Botuobinsky oil and gas condensate field in the period 2000-2015 by the main abiotic components of the ecosystem.

Chemical and analytical work carried out in the laboratory of physical and chemical methods of analysis of Institute of Applied Ecology of the North by methods of capillary electrophoresis and atomic absorption spectrometry. Each analysis was performed in double repeat at $\mathrm{d}=15-30 \%, \rho=0,95$. 


\section{Results and discussion}

Srednebotuobinsky oil and gas deposit is confined to the local structure, located on the northern slope of the Mirny protrusion in Malo-Botuobinsky area - very difficult in terms of geology area, which is situated in the north-eastern periclinal ending of Nepsko-Botuobinsky anteclise [1]. The most elevated part of the anteclise is adjacent to the upper reaches Chona, Nuya and Peleduy. There was deposited rock salt, the possibility of including carnallite, sylvite, bischofite and some other minerals. The accumulation of interporous brine with enhanced mineralization is caused by very high salinity of these waters. Moreover, high-performance horizons of brines leaching of rock salt are formed in the zone of intensive water exchange.

Underground brines are rich in $\mathrm{Br}, \mathrm{Sr}$, rare alkalis and are industrial waters, from which many components can be extracted. The mineralization of brines, their geochemical guise is close to intersalt, and their composition is more homogeneous, the concentration of magnesium, bromine, strontium is slightly lower [2]. Development of oil and gas fields in difficult geological and hydrogeological conditions, where brines are considered as one of the main agents in the technological processes of oil and gas companies, determines a regular ecological and geochemical control of the territory. The main objects of monitoring, in this case, are the storage medium of terrestrial ecosystems - is the snow and soil cover, and water ecosystems - is the surface water hydrochemical composition of the main water flow and chemical composition of the sediment.

The sources of the trace elements in the snowpack are particles of soil and rocks, sea salt, products of industrial pollution [3]. The chemical composition of the snow cover is an indicator of processes of air migration of natural and technogenic substances and is subject to certain geographic regularities. Snow water as a rule has acidic or weakly acidic $\mathrm{pH}$, low mineralization. The most of the territory of Yakutia is characterized by a homogeneous bicarbonate sodiumcalcium chemical composition of snow. At the areas of the existing deposit wells, snow is characterized by weakly acidic $\mathrm{pH}$ with mineralization $8,4-14,9 \mathrm{mg} / \mathrm{dm} 3$ with very soft water. The composition of the snow water of predominantly hydrocarbonate class with a predominance of calcium and magnesium cations. Increased of saline and solid phases of snow on the sites of well are characterized by an unidirectional vector in the direction of the prevailing winds from the west and north-west direction (Figure 1). The bulk of analyzed ash elements are in a soluble state, in the microelement composition of snow waters are fixed $\mathrm{Mn}, \mathrm{Cu}$ and total Fe.

a)

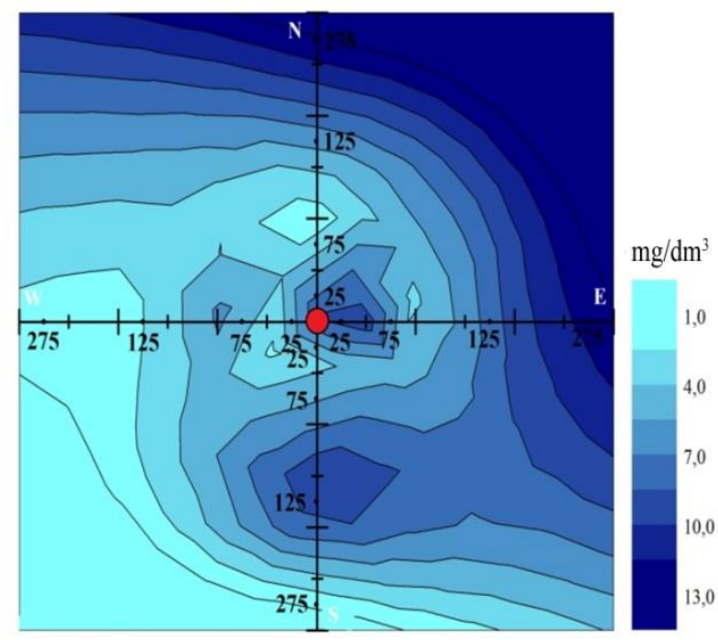

b)

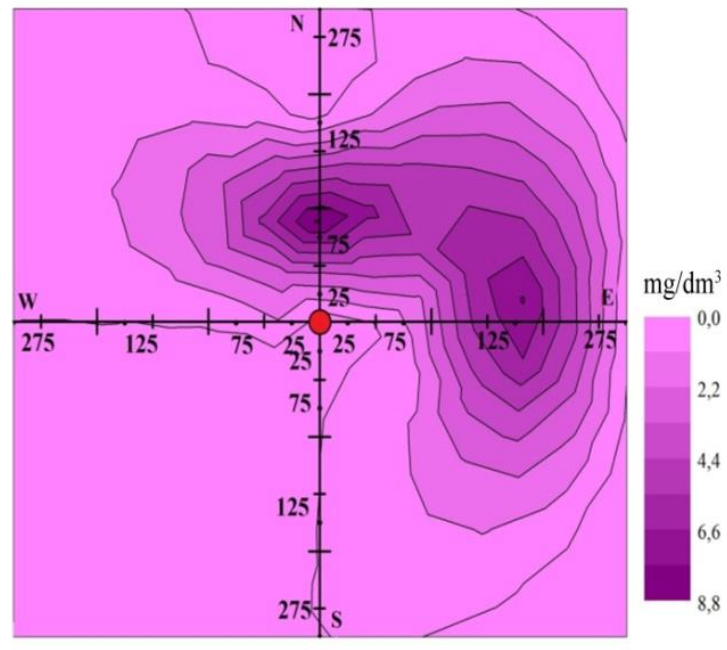

Fig.1: distribution of weighted (a) and mineral (b) substance in the snow water on the grounds of existing wells Sredne-Botuobinsky oil and gas well field ( $O$ - site of well; the numbers on the axes shows the distance from the well site, in meters).

Soil is one of the most informative units of the natural landscape, as it concentrates in itself the geochemical characteristics of rocks, vegetation, surface water and groundwater.

The soil is regarded not only as a tablet, concentrating industrial pollution, but also as the environment, which carries in itself the genetic attributes of the depositing components of landscape-geochemical systems in ecological and geochemical assessment of the current state of the landscape [4]. 
The soils of watersheds on the research territory by the basic genetic traits is attributed to cryogenic accumulativehumus, among whom studied and characterized cryogenic sod-carbonate in combination with cryogenic humus-carbonate, cryogenic fawn, fawn-brown, peaty and underdeveloped soils [5]. In general, soils of nature landscapes of the study area are characterized by a slightly acid or close to neutral $\mathrm{pH}$ in the upper organic horizons and slightly alkaline $\mathrm{pH}$ in the mineral part of the soil profile. Sufficiently high humus content and high cation exchange capacity, which generally defines the high sorption capacity of soil material and, therefore, low resistance of these types of soils to chemical contamination of soil [6].

Soils of technogenic-transformed landscapes are characterized by slightly alkaline and alkaline $\mathrm{pH}$, organic content and cation exchange capacity widely varies. As a rule, soils of technogenic-transformed landscapes are characterized by friable sandy size of particles. In the aggregate indicators as a rule sorption capacity of soils is very low and depends on impurities of natural organic matter of soils. Therefore, resistance to contamination in soil varies from low (in high organic content) to low (in case the no admixture of natural soil material).

Ecological and geochemical characteristics of the soil cover of the territory of oil fields was given on the base of an analysis of mobile forms content of nine trace elements - $\mathrm{Pb}, \mathrm{Zn}, \mathrm{As}, \mathrm{Cd}, \mathrm{Mn}, \mathrm{Cr}, \mathrm{Ni}, \mathrm{Co}, \mathrm{Cu}$ and their accumulation in natural and technogenic-transformed landscapes. On the example of microelement characteristics of soil cover on the territory of Srednebotuobinsky oil and gas field were traced variation of the content of mobile forms of trace elements in soils in the last four years (Figure 2).

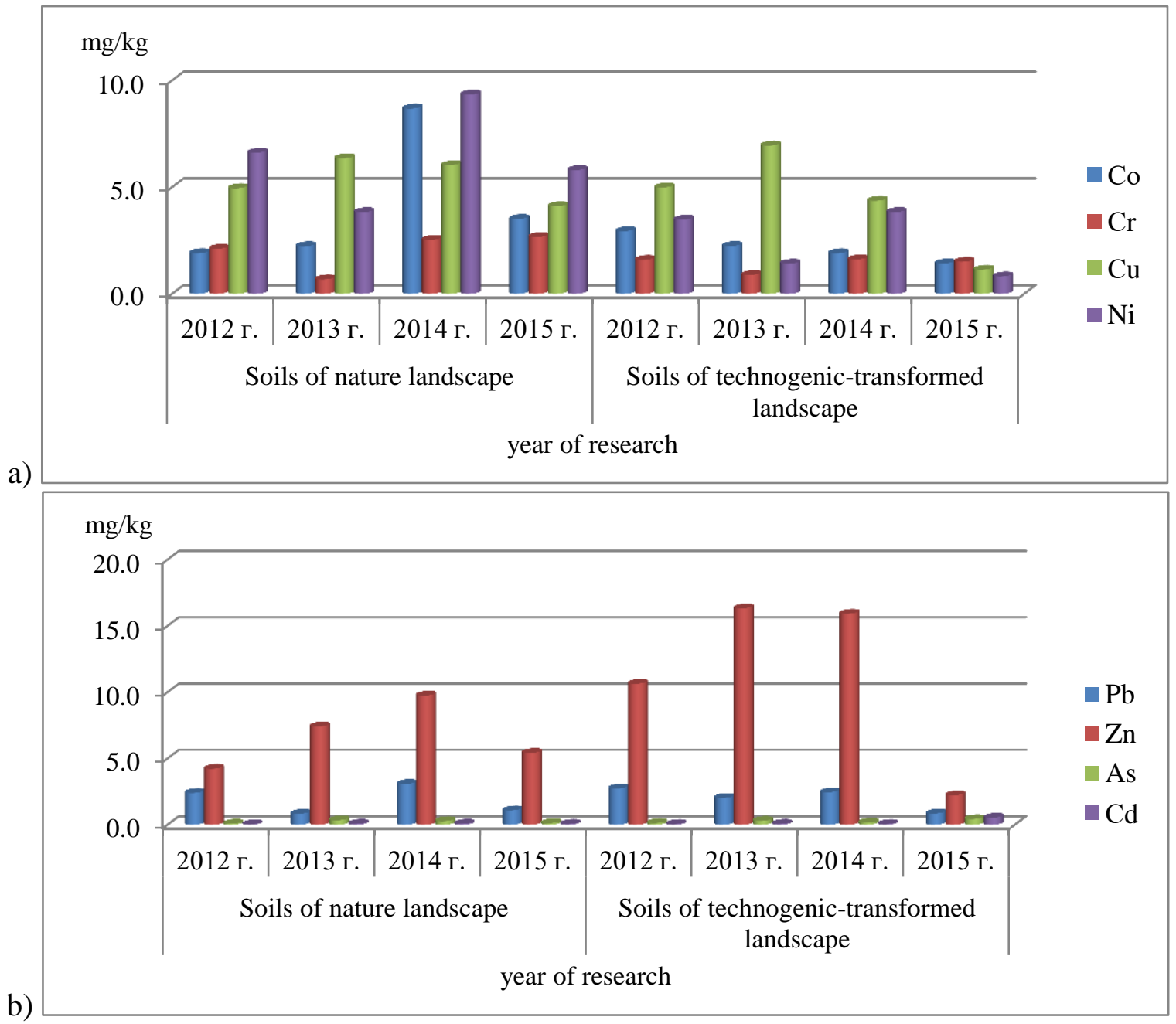

a) elements typomorphic kimberlites, b) elements, I hazard class

Fig. 2: Comparison of the average content of mobile forms in soils at areas Srednebotuobinsky oil and gas field. 
The tendency of concentrations reduction of elements in the soils of technogenic-transformed landscape forming the natural geochemical anomalies, the accumulation of which was fixed in all components of the ecosystem of study area $\mathrm{Ni}, \mathrm{Cr}$, Co was noted.

And conversely, in the soil technogenic-transformed landscapes it is increased the share of mobile forms of microelements that are not specific to the soils of the study area - $\mathrm{Pb}, \mathrm{Zn}$, As, $\mathrm{Cd}$ and, in this case, are the markers of technogenic transformation of landscapes due to ongoing work on the site of the well field.

Thus, the microelements characteristic of the soil depends on the properties of the material itself, since the predominance of sandy fraction particle size determines the low sorption capacity. Soils of technogenic landscapes, transformed as a result of extraction of hydrocarbons in the territory of the investigated fields $\sigma$ can be a source of secondary pollution to neighboring environments by mobile forms of elements of the first class of danger.

The degree of the impact can be seen by state of the main large watercourse Ulakhan Botuobiya river, flowing through the catchment area of Srednebotuobinsky oil and gas field. Natural surface waters are characterized by a homogeneous, mainly sulphate-bicarbonate-calcium-magnesium composition at the time of observation in 2015. The relationship of watercourse with groundwater is indicated by manifestations of strontium and barium, as well as an increase in the concentration of chloride and sodium in water on some parts of the river.

The amount of mineralization varies from 77.4 to $144 \mathrm{mg} / \mathrm{dm} 3$ and down by the flow there is marked its decrease by reducing the concentrations of major ions (Figure 3). In the microelemental composition were fixed copper, zinc and total iron in small quantities. Changes in value of mineralization in natural watercourses in the area of oil and gas production are presented on the example of the universal indicator hydrochemical composition - the value of water mineralization (Figure $3)$.

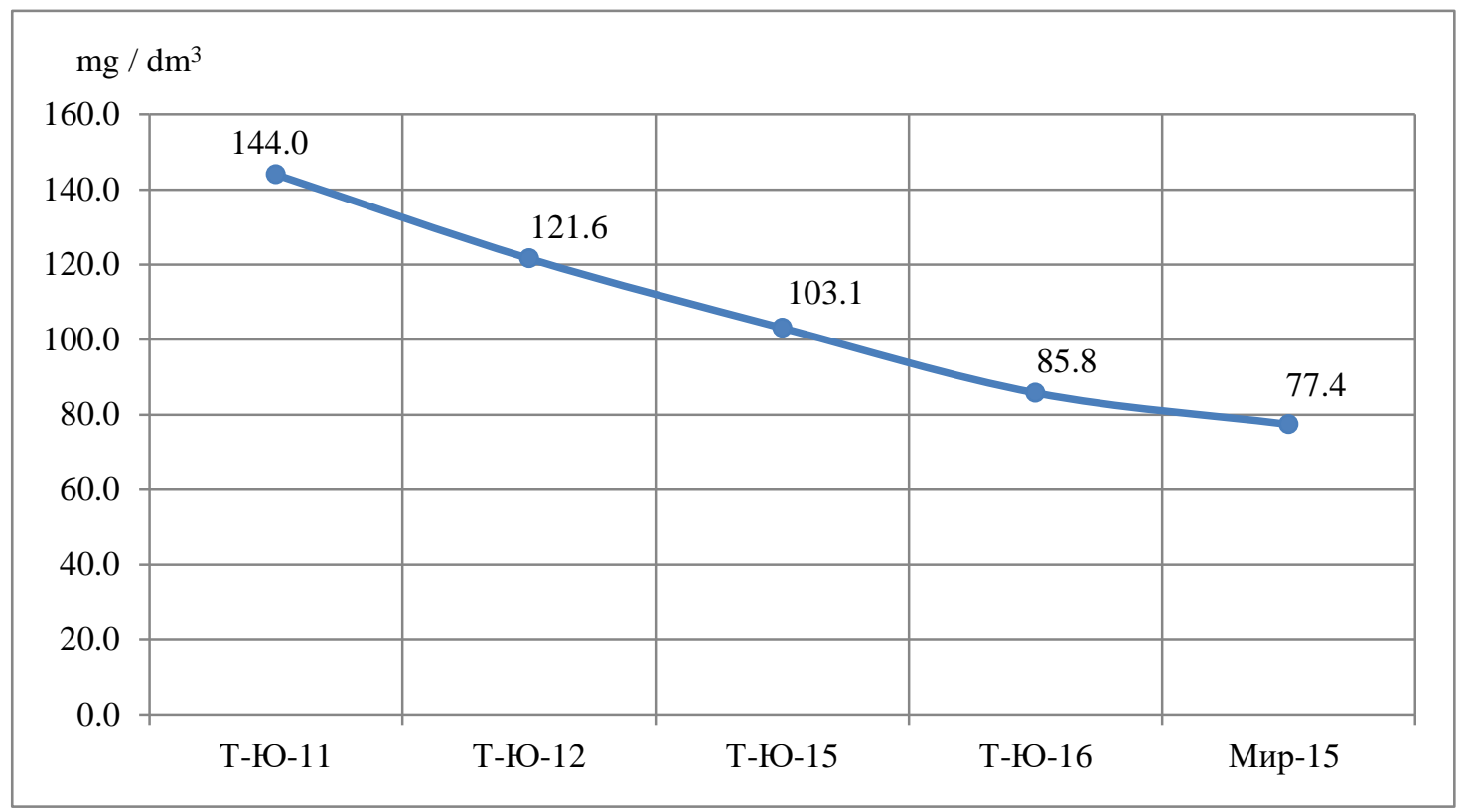

Fig. 3: Dynamic of changes the magnitude of mineralization and major ions in the water of the river Ulakhan Botuobiya.

In the riverhead of Taas Yuriakh there are located Srednebotuobinsky oil and gas fields. Water is characterized by low mineralization practically throughout the river Ulakhan Botuobiya. Thus, at the time of research activities of the oil and gas complex there was no significant impact on the quality of natural water.

The sediments are an important component of water ecosystem, accumulator and simultaneously depositing surroundings of different pollutants in system of the water surface - sediment. Sediments of tributaries of river Ulakhan Botuobiya are characterized by neutral and weakly alkaline medium with a very low organic carbon content to $2.2 \mathrm{wt} . \%$, in the composition of a water-soluble complex by the dominant ions are bicarbonates, chlorides, sodium and calcium. The microelement spectrum of sediment river Ulakhan Botuobiya which characterizes the accumulation of mobile forms of trace microelements looks as follows: Ni7,2 $\rightarrow$ As2,9 $\rightarrow \mathrm{Cr} 2,3 \rightarrow \mathrm{Cu} 2,0 \rightarrow \mathrm{Cd} 1,8$. Despite the fact that in the soils and 
sediments there is accumulation of both elements characteristic for this area, and markers technogenesis. Any patterns of distribution of microelements in system soil-sediment - surface water were not revealed. Herewith in the results of the analysis of the water-soluble salts content it was established the dependence of content of sodium, sulphate and chloride in the system soil - sediment - water surface (Fig. 4). These indicators with enough high degree of probability confirms that the high content, such as sodium, may be as a the result not only of technogenic impact of industrial facilities of the oil field, but also are a logical natural phenomenon, reflecting the impact a cambrian aquiferous complex.
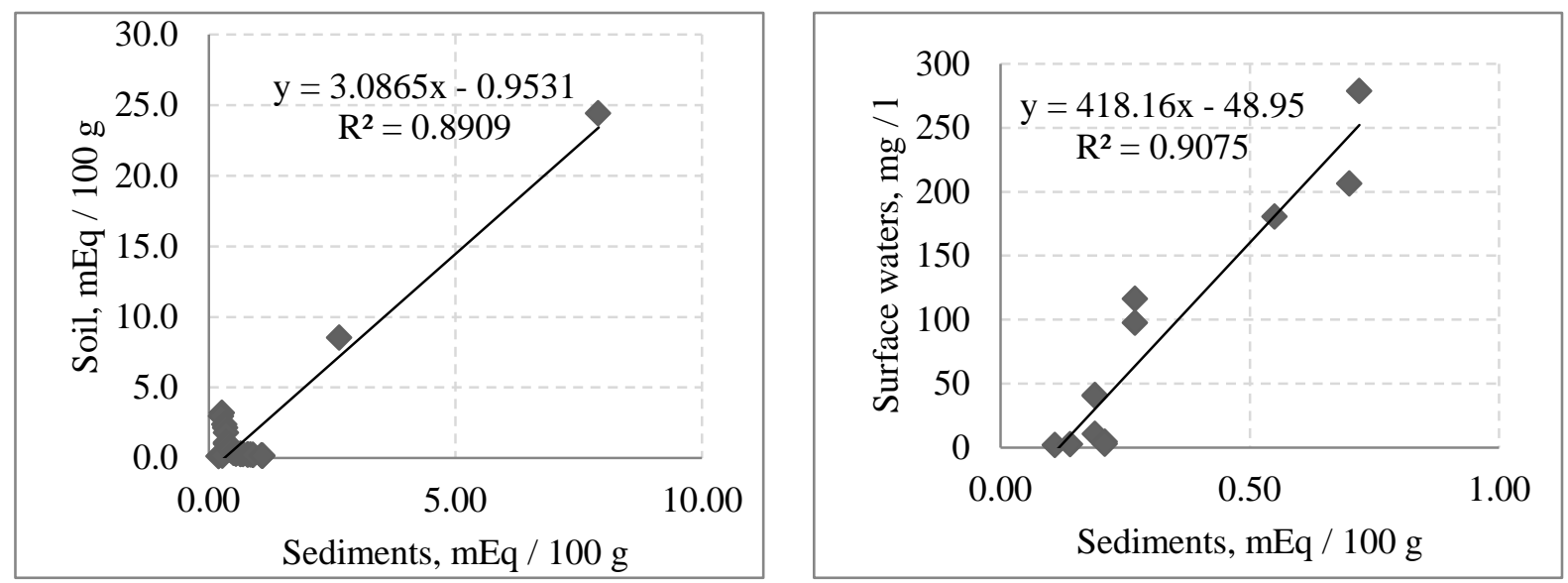

Fig. 4: The dependence of changes in the content of sodium in the system soil - sediment - surface water.

\section{Conclusion}

The analysis of the state of the major abiotic components of the ecosystem of oil field territory in terms of territory of Srednebotuobinsky oil and gas field on content and extent of the migration of mobile forms of nine trace elements allows to draw some conclusions that the impact of oil and gas complex in the region of Western Yakutia is manifested locally, but it is irreversible. As part of the elements that manifest in all the abiotic components are fixed symbolic contents of mobile forms of $\mathrm{Mn}, \mathrm{Co}, \mathrm{Ni}, \mathrm{Cu}, \mathrm{Cd}$ and $\mathrm{Zn}$.

\section{References}

[1] A. F. Safronov, Oil and gas fields of Yakutia, in Tectonics, geodynamics and metallogeny of the territory Republic of Sakha (Yakutia). Moscow: Nauka, pp. 421-446, 2001.

[2] Y. B. Legostaeva, V. F. Popov, M. I. Ksenofontova, S. V. Nesterova, "Hydrogeochemical indicators in the components of terrestrial and aquatic ecosystems of Irelyakhsky oil and gas field," Exploration and protection of mineral resources, no. 11, pp. 47-51, 2015.

[3] V. N. Makarov, N. F. Fedoseyev, V. I. Fedorov, Geochemistry snow of Yakutia, Yakutsk: Permafrost Institute of SB RAS, 1990.

[4] Y. B. Legostaeva, "Geochemical characteristics of frozen soils of the southwestern Yakutia," in Soils, plant and animal life of the Southwest Yakutia, Novosibirsk, pp. 17-22, 2006.

[5] B. S. Yagnyshev, T. A. Yagnysheva, M. N. Zinchuk, J. B. Legostaeva, Ecology of Western Yakutia (geochemistry geosystems: Status and Challenges). Yakutsk, 2005.

[6] A. G. Dyagileva, "The stability of permafrost soils to chemical contamination by the criteria of sorption of soil material," in Proceedings of the 3 All-Russian Conference of Young Scientists "Biodiversity: global and regional processes, "Ulan-Ude, pp. 122-123. 